\title{
CO-GESTÃO ADAPTATIVA EM ÁREAS PROTEGIDAS: REFLEXÕES A PARTIR DA ESTAÇÃO ECOLÓGICA DE GUARAQUEÇABA, PARANÁ
}

Guilherme Tebet ${ }^{1}$ Micaela Trimble ${ }^{2}$

Resumo: Este artigo analisa, a partir do enfoque da co-gestão adaptativa, o conselho consultivo da Estação Ecológica de Guaraqueçaba no Paraná. Para isso foram realizadas entrevistas, questionários, observação participante e análise documental entre 2014 e 2017. Os resultados apontam obstáculos em garantir a participação legítima e efetiva dos diferentes atores sociais, baixo grau de compartilhamento de poder e a baixa articulação vertical com outras escalas institucionais, dificultando a gestão dos conflitos, a transparência na gestão e a adequação da unidade conservação à realidade local.

Palavras-chave: Gestão participativa. Unidades de conservação. Conselhos. Áreas protegidas. Gestão de conflitos.

\section{ADAPTIVE CO-MANAGEMENT IN PROTECTED AREAS: REFLECTIONS FROM THE ECOLOGICAL STATION OF GUARAQUEÇABA, PARANÁ}

\begin{abstract}
This article analyzes, through the adaptive co-management lens, the consultative council of the Ecological Station of Guaraqueçaba in Paraná. Interviews, questionnaires, participant observation and document analysis were undertaken between 2014 and 2017 . The results show that conflict management, transparency, and fit of the conservation unit to the local reality are hindered by obstacles for a legitimate and effective participation of the different stakeholders, a low degree of power sharing, and limited vertical connections with other institutional scales.
\end{abstract}

Keywords: Participatory management. Conservation units. councils. Protected areas. Conflict management.

\section{CO-MANEJO ADAPTATIVO EN ÁREAS PROTEGIDAS: REFLEXIONES DE LA ESTACIÓN ECOLÓGICA DE GUARAQUEÇABA, PARANÁ}

Resumen: Este artículo analiza, a partir del enfoque del co-manejo adaptativo, el consejo consultivo de la Estación Ecológica de Guaraqueçaba en Paraná, Brasil. Se realizaron entrevistas, cuestionarios, observación participante y análisis documental entre 2014 y 2017. Los resultados muestran que la gestión de los conflictos, la transparencia en la gestión y la adecuación de la unidad de conservación a la realidad local, se ven dificultadas por obstáculos en garantizar la participación legítima y efectiva de los diferentes actores sociales, el bajo grado de división de poder y la baja articulación vertical con otras escalas institucionales.

Palabras-clave: Gestión participativa. Unidades de conservación. Consejos. Áreas protegidas. Manejo de conflitos.

\footnotetext{
${ }^{1}$ Universidade Federal de Santa Catarina, Pós-graduação em Geografia, Florianópolis, Brasil, guitebet@hotmail.com. https://orcid.org/0000-0002-2399-1287

2South American Institute for Resilience and Sustainability Studies (SARAS), Bella Vista-Maldonado, Uruguay, mica.trimble@gmail.com. https://orcid.org/0000-0002-1971-4471
} 


\section{Introdução}

O conceito de sistema socioecológico aponta para o fato de que os componentes sociais e ecológicos interagem entre si de forma dinâmica e não linear, gerando um sistema complexo e pouco previsível (FOLKE et al., 2002). Portanto, os enfoques tradicionais de gestão dos recursos naturais que partem do princípio de ecossistemas em equilíbrio e baseados na noção de 'comando-e-controle' a partir de abordagens centralizadoras ('top-down management') devem ser substituídos por soluções inovadoras (ACHESON, 2006; HOLLINGS; MEFFE, 1996; OLSSON et al., 2004). Uma abordagem de gestão emergente que vem sendo proposta para lidar com sistemas socioecológicos complexos é a co-gestão adaptativa (CGA), que articula a necessidade do compartilhamento de poder entre diferentes atores com a importância do aprendizado contínuo (ARMITAGE et al., 2009).

Partindo do princípio de que os sistemas socioecológicos são dinâmicos e que comunidades humanas que dependem diretamente de recursos naturais vêm experimentando rápidas mudanças socioeconômicas, a CGA propõe que a gestão seja entendida enquanto um sistema flexível de manejo de recursos em condições de se adaptar as mudanças inerentes a estes sistemas e capaz de lidar com as incertezas (ARMITAGE et al., 2009). Ou seja, a gestão não deve ser vista enquanto um conjunto de normas e padrões de comportamento fixos e pré-definidos, mas sim encarada enquanto um processo em que arranjos institucionais voltados para o uso de recursos naturais são construídos, testados e revisados de maneira continuada (OLSSON et al., 2004). Se os sistemas socioecológicos mudam constantemente, os processos de gestão devem incorporar atores sociais capazes de identificar mudanças e alterações neste sistema, por isso a CGA enfoca na importância da participação dos atores locais que usam diretamente os recursos (BERKES, 2007a). No entanto as mudanças ecológicas locais estão diretamente conectadas a processos mais amplos com dinâmicas muitas vezes imperceptíveis em escala reduzidas. Da mesma forma o sistema social, que com a globalização se encontra cada vez mais articulado em redes, também tem uma dinâmica fortemente influenciada por fatores externos à escala local (ARMITAGE et al., 2009). Por isso, a gestão deve permitir a criação de arranjos institucionais visando a comunicação vertical e horizontal entre atores sociais em diferentes escalas de atuação (BERKES, 2007a; OLSSON et al., 2004). Para a CGA estes arranjos multi-escalares devem permitir o compartilhamento de responsabilidades e o poder de decisão sobre o uso de recursos naturais, bem como ser uma arena de comunicação e diálogo de 
saberes (incluindo diferentes matrizes de conhecimento) que permita o aprendizado coletivo (BERKES, 2007a; OLSSON et al., 2004). Por fim, a co-gestão adaptativa, enquanto enfoque alternativo de manejo de recursos naturais, tem como objetivo buscar solução para problemas reais através de processos colaborativos que impulsionem modos de vida ecologicamente sustentáveis (PLUMMER; ARMITAGE, 2007), tornando o sistema socioecológico mais robusto às mudanças (OLSSON et al., 2004).

A conservação da biodiversidade é um tema de destaque dentro da discussão sobre gestão de recursos naturais, e a criação de áreas protegidas (AP) como ferramenta para alcançar esse objetivo é amplamente utilizada ao redor do mundo (BERKES, 2007b; FAO, 2012; POMEROY et al., 2014). Por outro lado, a criação de AP não pode ser vista como uma panaceia, já que o seu sucesso depende de múltiplos fatores (CHUENPAGDEE et al., 2013; JENTOFT et al., 2004). Visando dar conta desta complexidade, enfoques que consideram não apenas os aspectos ecológicos da conservação, mas também as dimensões humanas e os impactos socioeconômicos destas políticas vêm sendo propostos (CHARLES; WILSON, 2008; CHUENPAGDEE et al., 2013; FAO, 2012). Neste sentido, a participação de atores locais na construção de estratégias visando à conservação vem sendo apontada como um caminho promissor (BERKES, 2007b; KALIKOSKI, 2007).

No Brasil, as políticas de gestão ambiental passaram a estimular o envolvimento e a participação social, principalmente a partir da promulgação da Política Nacional de Meio Ambiente em 1982 e a Constituição Nacional de 1988 (CUNHA; COELHO, 2009; LOUREIRO; CUNHA, 2008). Em relação as AP, o Sistema Nacional de Unidades de Conservação (SNUC), promulgado em 2000, é um instrumento jurídico que merece destaque. Ele estabelece parâmetros para a criação e manejo das AP no Brasil. Segundo o SNUC as unidades de conservação são divididas em dois grupos: as unidades de Proteção Integral, onde o uso direto dos recursos naturais não é permitido, e as unidades de Uso Sustentável. Estabelece também que a gestão destas áreas, embora de responsabilidade do Estado, deve ser realizada com participação social (BRASIL, 2000; CASTRO JÚNIOR et al., 2009). Como principal instrumento de gestão participativa das Unidades de Conservação (UC) está a obrigatoriedade de se estabelecer conselhos consultivos ou deliberativos ${ }^{3}$. Segundo o Instituto Chico Mendes de Conservação da

\footnotetext{
${ }^{3}$ Os conselhos consultivos não tem poder de decisão sobre a gestão da UC, mas prestam assessoria e apoio ao órgão gestor do estado (ICMBio). Apenas nas Reservas Extrativistas e nas Reservas de
} 
Biodiversidade (ICMBIO), o Conselho em unidade de conservação é uma instância colegiada, um espaço de decisão onde há representantes de diversos grupos, cuja função é "constituir-se em um fórum democrático de diálogo, valorização, participação e controle social, debate e gestão da Unidade de Conservação" (ICMBIO, 2014, p.1)

Segundo o decreto que regulamenta o SNUC e a Instrução Normativa do ICMBIO sobre os conselhos em unidades de conservação, estes têm por princípios: garantir a conservação da biodiversidade; garantir equidade nas condições de participação dos diferentes atores; a valorização e respeito à diversidade socioambiental e do conhecimento tradicional. Segundo esses documentos, compete ao conselho: conhecer, discutir e propor ações da UC; promover ampla discussão sobre a efetividade da UC; e acompanhar e propor ações para monitoramento e avaliação dos instrumentos de gestão da UC (BRASIL, 2002; ICMBIO, 2014).

Ainda que a criação dos conselhos gestores em UC no Brasil não esteja diretamente vinculada à emergência do conceito da co-gestão adaptativa de recursos naturais, é possível traçar alguns paralelos entre ambos, como mostra a tabela 1.

Tabela 1: Semelhanças entre os conselhos em Unidades de Conservação do Brasil e a cogestão adaptativa.

Elementos chaves do conceito da co- Princípios, diretrizes e objetivos do gestão adaptativa conselho gestor em UC

\begin{tabular}{|c|c|}
\hline $\begin{array}{c}\text { Participação dos atores sociais relevantes ao } \\
\text { recurso ou sistema em questão }\end{array}$ & $\begin{array}{l}\text { Garantir a participação de diferentes atores } \\
\text { sociais }\end{array}$ \\
\hline Gestão colaborativa dos recursos & $\begin{array}{c}\text { Controle social e transparência da política de } \\
\text { conservação; propor medidas de gestão }\end{array}$ \\
\hline Resolução de conflitos & Promover a gestão de conflitos \\
\hline $\begin{array}{l}\text { Potencial de aumentar congruência entre } \\
\text { instituições sociais e sistema biofísico }\end{array}$ & $\begin{array}{c}\text { Garantir a conservação da biodiversidade e } \\
\text { adequar a UC à realidade local }\end{array}$ \\
\hline Aprendizado social & $\begin{array}{l}\text { Espaço de diálogo e de monitoramento e } \\
\text { avaliação da gestão }\end{array}$ \\
\hline
\end{tabular}

Fonte: elaboração própria, a coluna da esquerda tem como base PLUMMER, et al. (2012), e a da direita BRASIL (2002) e ICMBIO (2014).

Desenvolvimento Sustentável é que o conselho é deliberativo, com poder de tomar decisões que envolvam a gestão e manejo da UC. 
O SNUC e seus posteriores regulamentações apresentam uma base consistente de institucionalização de uma gestão participativa, o que é, majoritariamente, condizente com o conceito da co-gestão adaptativa. Por outro lado, na prática, ainda há dificuldades na efetivação e no funcionamento destes conselhos que muitas vezes são espaços burocratizados, vazios de poder e ineficientes (ABERS, 2008; DAGNINO, 2004; LOUREIRO; CUNHA, 2008). Assim, visando identificar as potencialidades e obstáculos na gestão participativa em áreas protegidas, este artigo analisa, a partir do enfoque da co-gestão adaptativa, o Conselho Consultivo da Estação Ecológica de Guaraqueçaba (COSEC), uma UC de proteção integral no litoral do Paraná, com histórico de conflito com populações tradicionais.

Depois de descrever a área de estudo e os métodos utilizados, a seção de resultados está dividida em três partes: a primeira caracteriza a estrutura de funcionamento do conselho, a segunda apresenta os problemas de representatividade, e a terceira analisa os mecanismos de compartilhamento de poder. A seção da discussão retoma os paralelos entre o conceito da co-gestão adaptativa e os princípios e diretrizes do conselho. Nas considerações finais apontamos quais os aportes que a co-gestão adaptativa pode trazer para o funcionamento dos conselhos em UC.

\section{Área de Estudo}

A Estação Ecológica (ESEC) de Guaraqueçaba é uma UC de proteção integral, criada em 1982 com objetivo de preservar os manguezais do município de Guaraqueçaba, no interior do Complexo Estuarino da Baía de Paranaguá (Paraná). Na mesma região da Baía de Paranaguá, existem mais duas UC, o Parque Nacional (PARNA) de Superagui, também de proteção integral, e a Área de Proteção Ambiental (APA) de Guaraqueçaba, de uso sustentável, conforme indica a Figura 1 abaixo. A região do litoral do Paraná, onde estão localizadas estas UC, é onde há os maiores remanescentes do bioma de Mata Atlântica do país (ISA, 2008). Também nesta região, existem muitas comunidades tradicionais que têm como principal fonte de renda e subsistência a pesca (ANDRIGUETTO-FILHO, 2002). No entorno e no interior da ESEC de Guaraqueçaba, a extração de caranguejo-uçá (Ucides cordatus) e outras espécies diretamente relacionadas com os manguezais é a principal fonte de subsistência de muitas destas comunidades (FARACO, 2012; PAULA et al., 2015). 


\section{Metodologia}

A pesquisa foi realizada entre novembro de 2014 e março de 2017, usando uma combinação de métodos complementares: entrevistas, questionários, observação participante e análise documental. Foram realizadas 18 entrevistas semiestruturadas (BUNCE, 2000; SEIXAS, 2005) com ICMBIO e os conselheiros do Conselho Consultivo da ESEC (COSEC) entre novembro de 2014 a abril de 2015. Dos entrevistados, sete eram representantes comunitários, quatro eram representantes de órgãos governamentais, três eram representantes de ONGs, três eram representantes de instituições de ensino, além de uma entrevista com o Movimento dos Pescadores Artesanais do Paraná - MOPEAR. Entre janeiro e março de 2017 foram aplicados nove questionários com objetivo de aprofundar algumas questões. Buscou-se aplicar o questionário com pessoas que já haviam sido entrevistadas anteriormente, sendo três representantes de ONGs, quatro representantes comunitários, um representante de órgão público e um representante de instituição de ensino.

Figura 1 - Mapa de localização da Estação Ecológica (ESEC) de Guaraqueçaba e outras UC na área de estudo no litoral do Paraná.

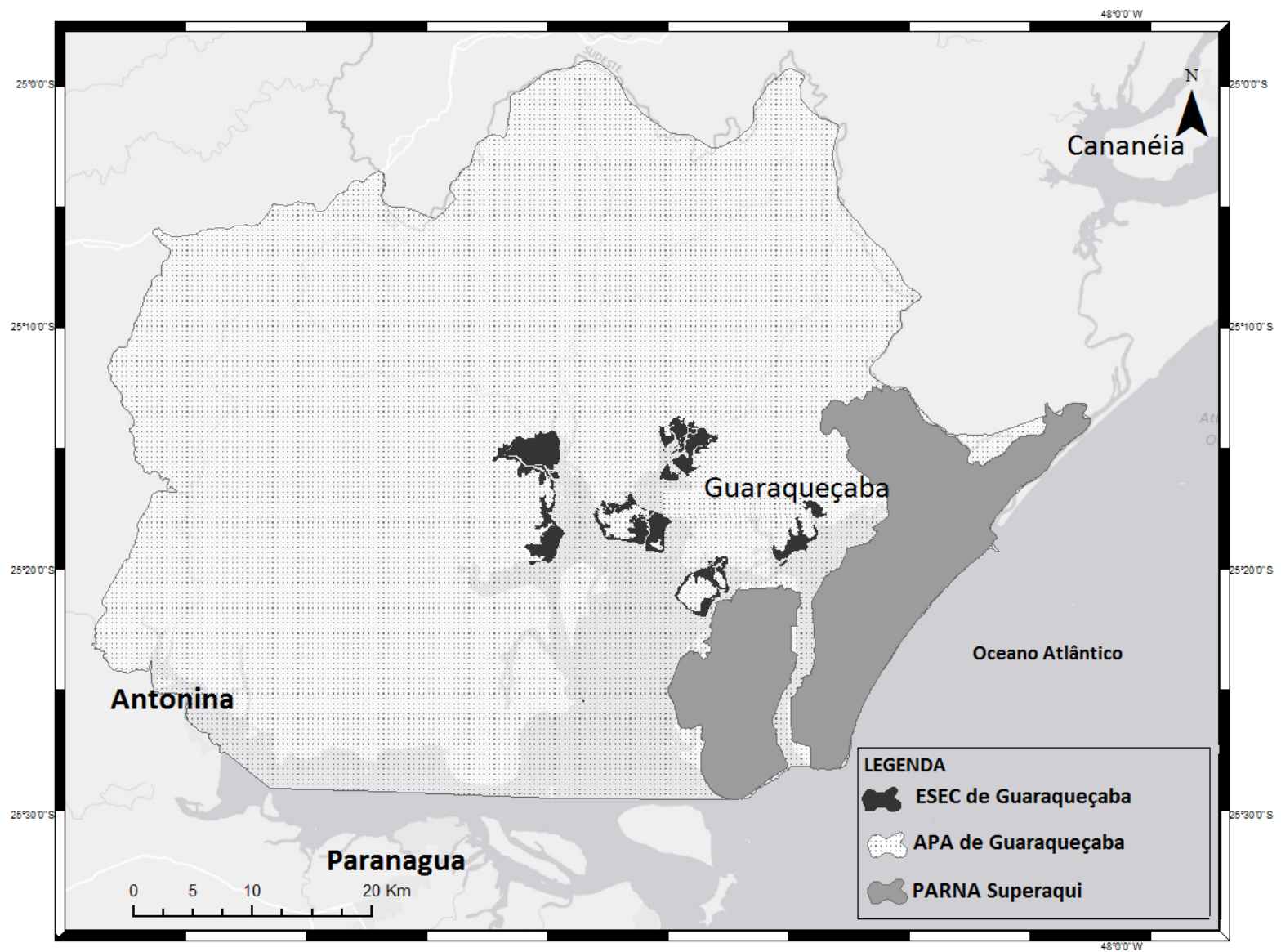

Fonte: Elaboração própria. 
A observação participante (BUNCE, 2000; SEIXAS, 2005) ocorreu no acompanhamento de duas reuniões do conselho, em novembro de 2015 e novembro de 2016 ( $6^{\circ}$ e $7^{\circ}$ reunião ordinária do conselho). Também houve o acompanhamento de duas atividades do ICMBio na comunidade do Almeida (outubro e novembro de 2016), referentes à construção do Termo de Compromisso, que é um dispositivo de gestão presente no SNUC visando a construção de um acordo que permita a permanência ou o uso dos recursos por populações tradicionais no interior das UC de proteção integral. Ademais, foram analisados documentos oficiais referentes ao conselho, entre eles: o regimento interno do conselho; três relatórios da reunião do grupo de trabalho que criou o conselho; oito relatórios de reunião com as comunidades para escolha de representantes para o COSEC; e oito atas das reuniões do COSEC entre maio de 2012 e novembro de 2016.

\section{Resultados}

\section{Criação, estrutura e funcionamento do Conselho da ESEC}

O COSEC foi criado no dia 5 de janeiro de 2012, trinta anos após a criação da UC de maneira centralizada e não participativa (TEBET; TRIMBLE; MEDEIROS 2018). Segundo a portaria de criação o COSEC tem como finalidade: "contribuir com ações voltadas ao efetivo cumprimento dos seus objetivos de criação e implementação do Plano de Manejo da Unidade" (ICMBIO, 2012). Segundo o regimento interno, aprovado em reunião (agosto de 2014), o conselho deve funcionar com base nas diretrizes estabelecidas pela instrução normativa (ICMBIO, 2014), já apresentadas na seção acima, e apenas adaptadas ao contexto local.

Entre sua criação em 2012 até o final de 2016, o conselho teve 7 reuniões ordinárias e uma reunião extraordinária (para discutir o regimento interno do conselho). Os temas mais discutidos foram referentes à pesca e ao uso dos recursos no interior da ESEC (6 reuniões); questões relacionadas a licenciamento e/ou condicionantes ambientais (5 reuniões); e discussões sobre o Plano de Manejo da ESEC e sobre o Termo de Compromisso (3 reuniões cada), como mostra a Tabela 2. Com base nos questionários, apenas um conselheiro (comunitário) discordou em algum grau que os temas tratados nas reuniões do COSEC eram relevantes e prioritários para a conservação da ESEC e para os atores sociais envolvidos. 
Tabela 2: Resumo dos principais temas discutidos nas reuniões do COSEC.

\begin{tabular}{cc}
\hline Data & Tipo \\
\hline $04 / 2012$ & I Reunião Ordinária
\end{tabular}

12/ 2013 II Reunião Ordinária

06/2014 III Reunião Ordinária

08/2014 I Extraordinária

11/ 2014 IV Reunião Ordinária

6/ 2015 V Reunião Ordinária

11/2015 VI Reunião Ordinária

11/ 2016 VII Reunião Ordinária
Principais temas discutidos

Funcionamento da Câmara Técnica de pesca; ordenamento da pesca; dissolução da Câmara

Técnica de licenciamento.

Plano de Manejo; Termo de Compromisso; pesca do caranguejo; renovação do Conselho; regimento interno.

Plano de Manejo; licença e condicionantes dos parques aquícolas; Termo de Compromisso; ordenamento da pesca do caranguejo. Regimento interno.

Plano de Manejo; licenciamento de parque aquícola; pesca do caranguejo; Termo de Compromisso.

Renovação do Conselho (falta de); licenciamento de parque aquícola; Plano de Ação do conselho.

Pesquisa de condicionante ambiental da dragagem do porto; pesca do caranguejo; Plano de Ação.

Pesca do caranguejo; Termo de Compromisso.

Fonte: atas das reuniões de $2012-2016$.

Por outro lado, as entrevistas mostraram que os conselheiros têm dificuldades em apontar pontos fortes relacionados ao conselho. A Tabela 3 sintetiza os pontos fortes e fracos identificados, separados por segmento social. Como ponto fraco comum entre os diferentes atores destaca-se a falta de ações concretas por parte do conselho ou de resultados efetivos; como ponto forte comum encontra-se a participação das comunidades locais.

Tabela 3: Pontos fortes e fracos do COSEC.

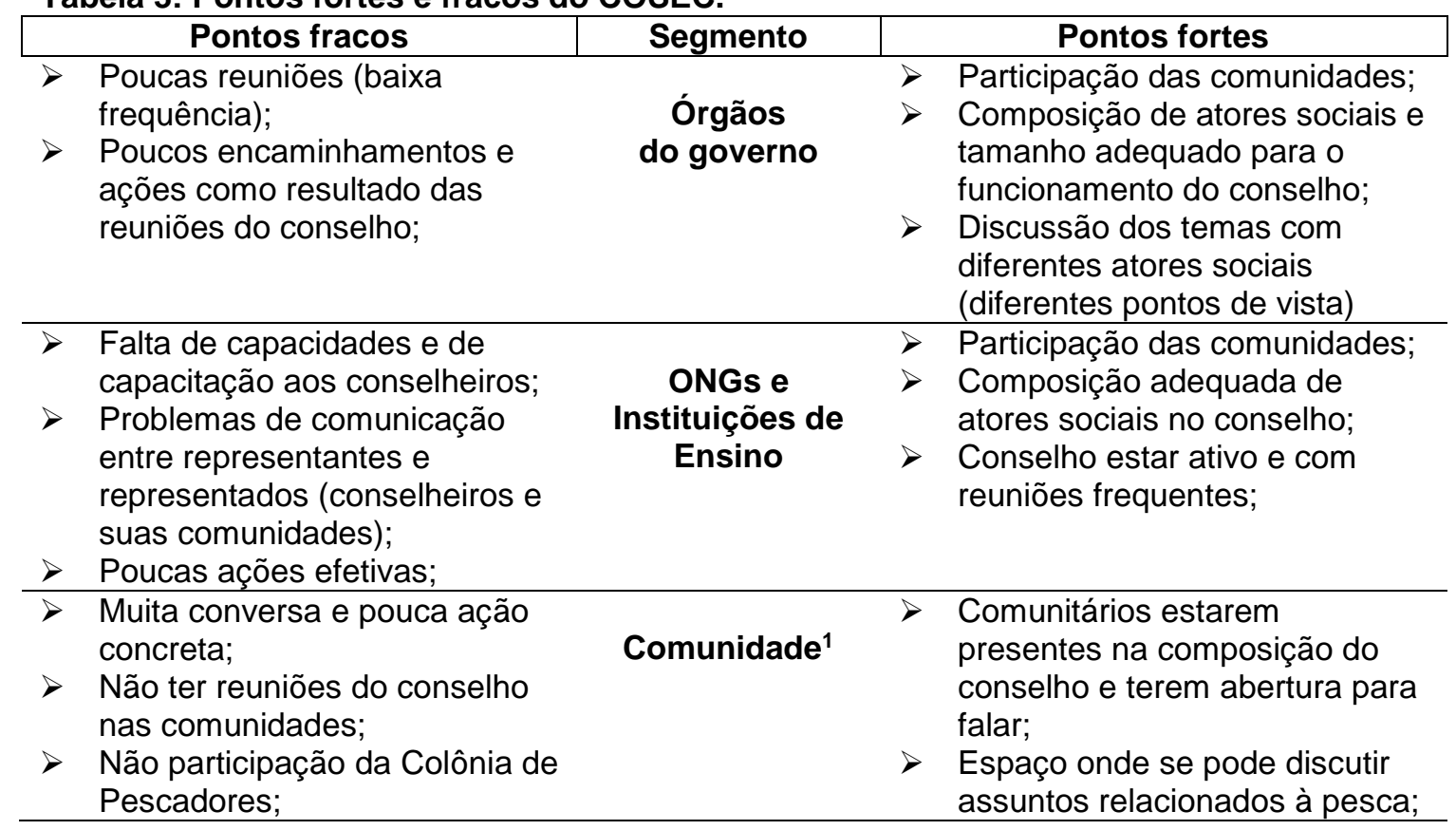


Fonte: entrevistas com conselheiros em 2014-2015.

${ }^{1}$ Nesta tabela o MOPEAR é considerado na categoria de comunidade, embora na composição do conselho ele seja enquadrado como sociedade civil.

\section{Representatividade}

$\mathrm{Na}$ Instrução Normativa sobre criação e funcionamento dos conselhos e no regimento interno há uma preocupação em estabelecer uma composição de membros no conselho que garanta a participação dos diversos setores envolvidos com a UC (ICMBIO, 2014). Na etapa de criação do COSEC, a composição foi decidida a partir de um grupo de trabalho liderado pelo ICMBIO que identificou os atores sociais e setores que deveriam ser representados. Buscou-se paridade de representação entre órgãos públicos, organizações da sociedade civil e população local (comunidades). As quinze vagas para membros do conselho ficaram distribuídas conforme mostra a Tabela 4.

Tabela 4: Composição do COSEC

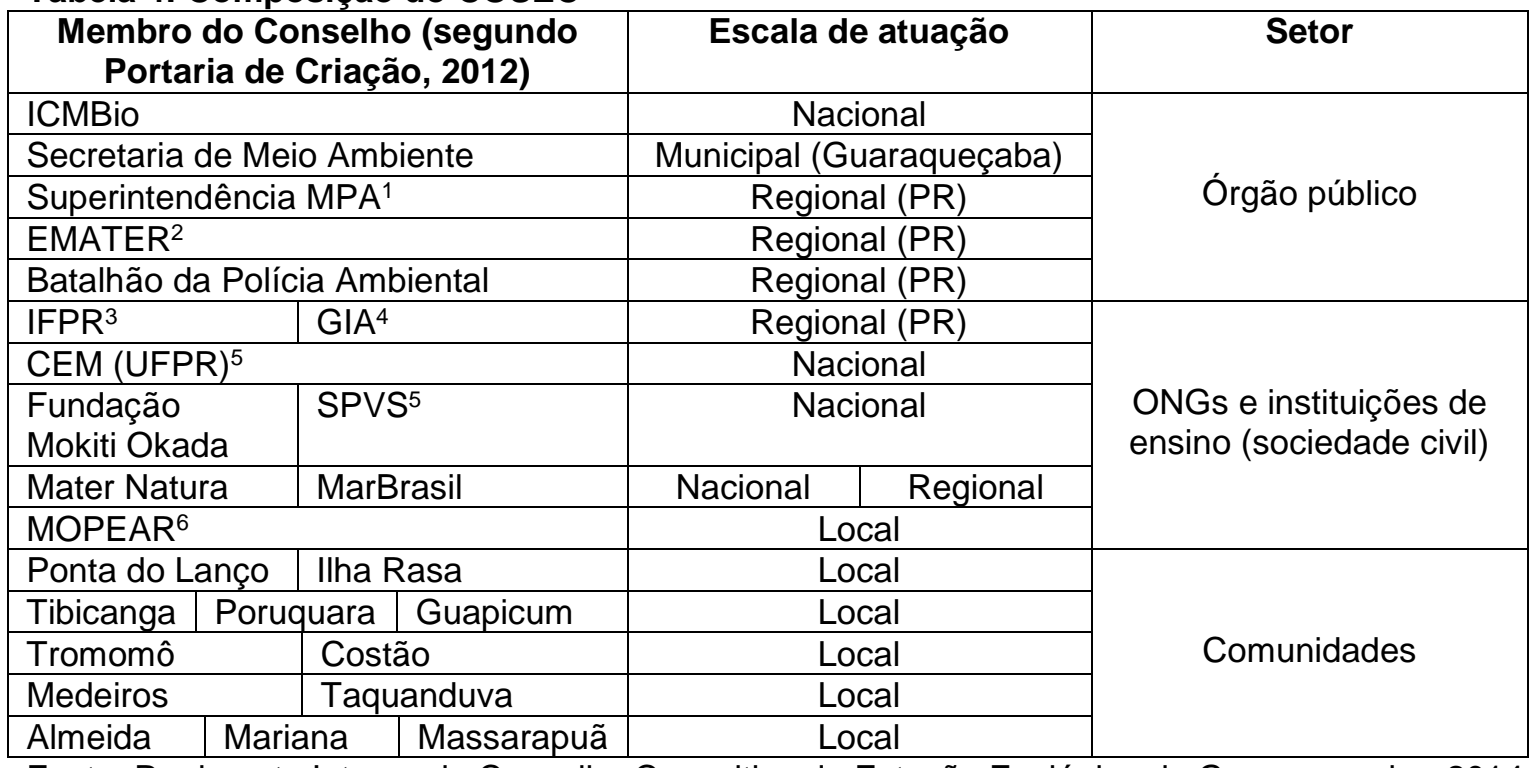

Fonte: Regimento Interno do Conselho Consultivo da Estação Ecológica de Guaraqueçaba, 2014.

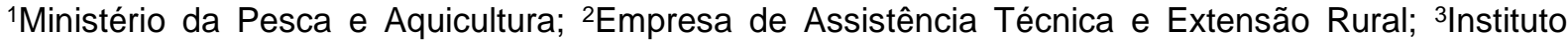
Federal do Paraná; ${ }^{4}$ Grupo Integrado de Aquicultura e Estudos Ambientais; ${ }^{5}$ Sociedade de Pesquisa em Vida Selvagem; ${ }^{6}$ Movimento dos Pescadores Artesanais do Paraná.

Durante as entrevistas, os órgãos públicos, instituições de ensino e ONGs consideraram a composição adequada para as discussões que vêm sendo feitas, enquanto que alguns comunitários apontaram para a falta da participação da Colônia de Pescadores Z-2 de Guaraqueçaba, do Instituto Ambiental do Paraná - IAP (órgão estadual do meio-ambiente que estabeleceu e fiscaliza regras de pesca) e de algumas comunidades que não tem vaga no conselho.

Uma questão a mencionar a respeito da representatividade no COSEC é o fato de que uma única vaga é ocupada por mais de um membro. É o caso das vagas 
destinadas à sociedade civil, onde quatro ONGs dividem duas vagas, sendo uma delas membro titular e outra membro suplente. Também é o caso das vagas destinadas às comunidades, onde uma vaga é representada por até três comunidades. Em entrevista, as ONGs não consideraram esta situação como um problema, por entenderem que seus interesses de atuação dentro do conselho são alinhados. Já os representantes comunitários mostraram preocupação; nas palavras deles: "na verdade teria que ter um (representante) para cada comunidade, porque uma comunidade tem realidade diferente da outra"; "acho que está errado isso ai porque tem dinâmica de trabalho diferente uma (comunidade) da outra"; "eu já falo pela minha comunidade, eu represento a minha comunidade; isso é uma coisa, representar outra comunidade é outra coisa, é outra responsabilidade."

No caso do COSEC, após estabelecida a composição de membros, a definição dos conselheiros (pessoas que irão representar as instituições membros) foi realizada por nomeação direta no caso dos órgãos públicos, instituições de ensino e ONGs, e a partir de reuniões organizadas pelo ICMBIO no caso das vagas destinadas às comunidades. O processo de comunicação entre conselheiros e instituições (ou comunidades) que representam foi identificado, pelos próprios conselheiros, como um dos pontos fracos (Tabela 3). Os dados das entrevistas e questionários apontam a falta de um procedimento preestabelecido e específico de comunicação sobre o conselho entre os membros de órgãos públicos e de ONGs. Nenhum dos conselheiros entrevistados faz reuniões sistemáticas com seus representados para discutir a pauta e os resultados das reuniões do COSEC. O mais comum é o repasse das pautas e das atas das reuniões. No caso dos conselheiros comunitários predomina a comunicação informal na própria comunidade e, em alguns casos, discussão na reunião da Associação de Moradores. Lembrando que uma vaga no conselho é destinada a até três comunidades, não identificamos nenhuma ação de diálogo e discussão, mesmo que informal, que envolvesse o conjunto dessas comunidades que se representam conjuntamente. Ainda que para efeitos legais este mecanismo de escolha de representantes seja legítimo, foi possível identificar problemas envolvendo a relação entre representantes e representados, principalmente nos conselheiros de comunidades. Ao menos três conselheiros comunitários declararam sofrer com a desconfiança da comunidade em relação a participação no conselho, que em alguns casos é visto como um vínculo de trabalho entre os comunitários e o órgão gestor. 
Durante as reuniões onde foram definidos os conselheiros comunitários, articulados e organizados pelo ICMBIO, 5 de 8 comunidades demonstraram não ter conhecimentos claros sobre os objetivos e limites da ESEC, e 7 explicitaram o interesse em discutir o uso dos recursos na área da UC. Também foi identificado que parte da desconfiança no conselheiro reside em uma expectativa não alcançada de que o conselho solucionaria os problemas relativos à pesca que as comunidades vêm enfrentando. Além disso, é constante a sugestão, por partes dos conselheiros comunitários, que as reuniões do conselho sejam realizadas nas comunidades, possibilitando maior participação, indicando de que de fato há problemas de comunicação e legitimidade entre representantes e representados.

Segundo o regimento interno do COSEC, o mandato dos conselheiros é de dois anos. Porém houve problemas na renovação do quadro de conselheiros, apesar do esforço do órgão gestor neste sentido a partir de 2015. As comunidades, por exemplo, tiveram dificuldade de planejar e executar processos autônomos e legítimos de escolha para novos representantes. Em alguns casos foram os antigos representantes que indicaram novos ou simplesmente continuaram a participar em nome de sua comunidade. Em poucos casos houve reunião específica para definir novos representantes (ou qualquer outro mecanismo de escolha).

Em relação aos órgãos públicos também houve dificuldades com a renovação. Dos cinco membros deste setor, somente um órgão público indicou formalmente novo conselheiro para ser seu representante (Polícia Ambiental). $O$ ICMBIO, apesar de membro, não precisa indicar conselheiros pois por lei o chefe da ESEC é o presidente do conselho. Um dos órgãos públicos membros, o Ministério da Pesca, deixou de existir em outubro de 2015. Os outros dois membros não indicaram conselheiros de maneira formal.

\section{Compartilhamento de poder e resolução de conflitos}

Embora em UC de proteção integral a legislação estabeleça que o conselho é apenas consultivo, e que a responsabilidade e autoridade na gestão seja centralizada no ICMBIO, o conselho ainda é a principal ferramenta voltada para uma gestão participativa, tendo autonomia e competência para discutir e propor ações de gestão, demandar ação aos órgãos competentes e propor formas para gestão e resolução de conflitos (ICMBIO, 2014). No COSEC, apenas dois conselheiros que responderam ao questionário (ambos pertencentes a ONGs) concordaram em algum 
grau que o COSEC tem tomado decisões que resultaram em melhorias significativas para a conservação dos manguezais. Analisando as atas das reuniões, é notável que poucas decisões ou propostas concretas de ações foram aprovadas. Uma das principais críticas ao conselho, principalmente dos comunitários, é justamente o fato de que há sempre muita conversa e discussão, mas pouca ação concreta (Tabela 3).

As entrevistas apontam que as principais expectativas dos conselheiros em relação às ações do conselho são a resolução do conflito de uso dos recursos no interior da unidade e a elaboração do Plano de Manejo. Embora sejam processos complexos e demorados, após mais de quatro anos de funcionamento do conselho estas expectativas não foram alcançadas.

No que tange a elaboração do Plano de Manejo, até o fim desta pesquisa, ela encontrava-se na fase inicial de diagnóstico. Em 2014 houve a criação de um Grupo de Trabalho para discutir este plano, com a nomeação de dois conselheiros (uma ONG e uma instituição de ensino) para participar deste espaço. Algumas propostas, como visitas nas comunidades para explicar o que seria o Plano de Manejo, e a construção participativa do diagnóstico inicial em que o Plano se basearia foram discutidas ao longo das três reuniões do COSEC que ocorreram em 2014. No entanto, segundo o gestor da UC, problemas referentes à articulação interna no próprio ICMBIO - entre a ESEC (escala local) e o ICMBIO sede (escala nacional), e a equipe local reduzida (recursos humanos), dificultaram os avanços no processo de elaboração do Plano de Manejo.

Já sobre as questões envolvendo o uso de recursos no interior da ESEC e o ordenamento da pesca, algumas ações foram realizadas. O SNUC estabelece a possibilidade de se firmar Termos de Compromisso entre comunidades tradicionais e o ICMBIO para permitir o uso de recursos dentro da UC de proteção integral. Impulsionadas pelas discussões no conselho, houve uma parceria entre a UFPR (membro do COSEC), o ICMBIO e algumas comunidades para fazer um monitoramento e diagnóstico da pesca do caranguejo no interior da ESEC, com objetivo de subsidiar tomadas de decisão, como por exemplo o Termo de Compromisso. Com base nos resultados desta pesquisa, e por demanda do conselho, houve um esforço, por parte do ICMBIO, de envolver outros órgãos públicos, através de reuniões para avançar com o ordenamento da pesca do caranguejo. Reuniões também foram realizadas nas comunidades para discutir 
exclusivamente o Termo de Compromisso, que também foi tema em três reuniões do conselho.

No entanto houveram dificuldades em concretizar o Termo de Compromisso. Há resistência de parte dos comunitários, incluindo o Movimento dos Pescadores Artesanais do Paraná. Os argumentos são a falta de confiança no órgão gestor, e o fato de que, por lei, o Termo de Compromisso ser um instrumento temporário. Para eles a resolução permanente seria o reconhecimento de que a UC foi criada em sobreposição ao território pesqueiro tradicional. Problemas acima mencionados de representatividade, notadamente a falta de reuniões nas comunidades e a falta de comunicação entre o conselheiro e sua comunidade, dificultam ainda mais o andamento do processo do Termo de Compromisso. Além disso, a área de pesca do caranguejo não incide apenas nas áreas da ESEC, mas também no Parque Nacional de Superagui e na Área de Proteção Ambiental de Guaraqueçaba. Outra questão relevante é que um dos principais problemas com a pesca do caranguejo diz respeito à proibição, por legislação federal e estadual, do uso de um petrecho conhecido como lacinho (petrecho confeccionado pelos pescadores e usado como armadilha nas tocas dos caranguejos), e não apenas com o fato da pesca ocorrer dentro da UC. Desta forma, o Termo de Compromisso se configura como um instrumento de gestão limitado devido à complexidade do problema a ser enfrentado. Os dados dos questionários apontam que ao menos os conselheiros comunitários têm este mesmo entendimento, já que todos eles discordam que o conselho seja um espaço adequado para lidar com os conflitos entre os usos e a conservação dos manguezais da ESEC de Guaraqueçaba.

\section{Discussão}

A institucionalização da obrigatoriedade da criação de conselhos em UC é um importante passo na busca para uma gestão mais participativa das áreas protegidas no Brasil. Na ESEC de Guaraqueçaba a criação do conselho aponta para uma fase de maior descentralização e principalmente de maior diálogo e comunicação entre órgão gestor e população local diretamente afetada pela criação da UC (TEBET, TRIMBLE, MEDEIROS, 2018). Analisar o conselho com base no conceito da cogestão adaptativa nos possibilita algumas reflexões sobre a potencialidade e obstáculos deste modelo de gestão. Retomaremos alguns dos paralelos entre a co- 
gestão adaptativa e os princípios e diretrizes dos conselhos (tabela 1) como base para a discussão.

\section{Participação de diferentes atores sociais}

O envolvimento dos atores sociais relevantes é apontado como uma das principais condições de sucesso na co-gestão adaptativa (LOUREIRO; CUNHA, 2008; REED, 2008; PLUMMER et al., 2012). A partir dos resultados apresentados identificam-se dois grandes desafios referentes ao envolvimento destes atores e que estão diretamente relacionados aos problemas de representatividade. O primeiro é garantir uma composição adequada de membros (atores sociais) que irão participar do conselho, e o segundo desafio é garantir mecanismos eficientes e legítimos de diálogo e comunicação entre o conselheiro e as instituições/comunidades por ele representadas.

Os resultados apontam que, de maneira geral, a composição do conselho é adequada, envolvendo órgãos púbicos, sociedade civil em várias escalas de atuação (local, regional, nacional), além das comunidades locais que utilizam diretamente os recursos no interior da UC. Já em relação ao segundo desafio, o arranjo institucional de participação do COSEC apresenta algumas inconsistências. A estrutura atual de funcionamento do conselho, baseada na realização de reuniões esporádicas, com a presença dos conselheiros 'eleitos' representantes de suas comunidades e instituições, não parece garantir o envolvimento eficiente dos diferentes atores sociais. A dificuldade em eleger seus representantes (conselheiros) de forma legítima e autônoma, e o pedido constante para haver mais reuniões nas comunidades, apontam para o fato de que esta estrutura organizativa não é adequada à atual forma de organização das comunidades locais. As comunidades são estruturas sociais complexas e não homogêneas (KEARNEY; BERKES, 2007); garantir mecanismos de participação que tenham maior legitimidade pelas comunidades ainda é um grande desafio. Bockstael, et al. (2016) e Araujo, et al. (2017) também apontam problemas de representatividade e legitimidade pelas comunidades nos processos de gestão participativa em outras áreas protegidas do Brasil.

O órgão público gestor deve estar aberto a se adaptar às condições locais evitando este descompasso entre estrutura de funcionamento do conselho e as dinâmicas das comunidades locais. Os processos de co-gestão adaptativa têm por objetivo aumentar a confiança entre os atores envolvidos (PLUMMER et al., 2012). 
No caso do COSEC foi identificado que houve aumento da confiança entre os conselheiros, mas também houve aumento da desconfiança entre comunitários e seus representantes no conselho, o que, em alguns casos gerou, conflitos intracomunitários.

\section{Controle social na política de conservação}

A desconfiança dos comunitários no conselho parece estar relacionada à incapacidade deste espaço em dar resoluções efetivas aos problemas enfrentados por eles, e o que se agrava ainda mais com a falta de um entendimento comum sobre o funcionamento e objetivos do Conselho, gerando falsas expectativas e descontentamentos. É interessante notar que a participação na gestão da ESEC se inicia 30 anos após a criação e gestão centralizada e não participativa da UC. Muitos comunitários, que utilizam diretamente os recursos no interior da ESEC, não têm conhecimento dos limites e restrições de uso impostas por este tipo de UC (TEBET, TRIMBLE, MEDEIROS, 2018). O conselho, devido aos problemas de representatividade acima mencionados, além dos limites inerentes a sua estrutura de funcionamento, não tem dado conta de reverter os problemas decorrentes de um processo histórico não participativo de criação e gestão da UC, que incluem a desconfiança das comunidades nos órgão públicos.

Destaca-se que em processos bem-sucedidos de gestão de recursos naturais, a participação se dá já nas etapas inicias, incluindo as de definição de objetivos e estrutura de funcionamento destes espaços (CHUENPAGDEE et al., 2013; REED, 2008; SANDSTROM et al., 2014). No caso do COSEC as comunidades foram chamadas a participar do conselho, que tem por um de seus objetivos "apoiar a efetividade da conservação da biodiversidade e a implementação dos objetivos de criação da Unidade de Conservação" (ICMBIO, 2014), após não terem sido incluídas na discussão sobre a criação desta UC e nem serem devidamente informadas sobre este processo.

A falta de transparência no momento de criação da UC, a participação tardia na gestão e a falta de esclarecimento prévio sobre as competências e estrutura de funcionamento do conselho, somados aos problemas de representatividade, fazem com que este espaço seja pouco efetivo em garantir o controle social e a transparência na política de conservação brasileira, mesmo sendo esta uma das diretrizes estabelecidas por lei. 
Armitage (2007) apontam que a co-gestão adaptativa não deve ser uma solução imposta, e que na maioria dos casos tanto as comunidades quantos os órgãos públicos não estão preparados para trabalhar conjuntamente de forma participativa (KEARNEY; BERKES, 2007). A co-gestão deve ser vista enquanto um processo, em que a aproximação e o empoderamento dos diferentes atores sociais envolvidos devem ser feitos de forma gradual, promovendo um nivelamento de informações e conhecimentos e criando condições mais propícias e legítimas de participação (ARMITAGE 2007; OLSSON et al., 2004; POMEROY; BERKES, 1997; TRIMBLE; PLUMMER, 2019). Não é o que parece estar acontecendo com os conselhos em UC. Segundo Araújo et al. (2017) a gestão participativa no Brasil ainda é parte de um processo altamente centralizado de tomada de decisão. No caso da ESEC de Guaraqueçaba os resultados apontam na mesma direção.

\section{Gestão de Conflitos}

A própria criação da ESEC de maneira não participativa e sobrepondo territórios pesqueiros de uso tradicional é encarada como fonte de conflito por parte dos atores sociais envolvidos. Assim, embora seja diretriz do conselho ser um espaço de gestão de conflito, a contradição é evidente: como gerir conflito através de um instrumento de gestão da ESEC quando ela mesma é a causa do conflito?

O principal conflito atual na ESEC é o uso direito de recursos naturais (pesca do caranguejo) no interior da UC. O Termo de Compromisso, que seria uma ferramenta de gestão possível de ser articulada a partir do COSEC e que minimizaria o conflito, está com dificuldade de ser aprovado devido à falta de confiança entre comunitários e órgão público. $E$, embora seja competência do conselho propor e demandar ações de gestão visando resolução de conflitos, outras ações que efetivamente reverteriam ou minimizariam os problemas decorrentes de um histórico centralizador e autoritário de criação e gestão da UC, como a desafetação, mudança de limites ou de categoria não podem ser tomadas pelo conselho. Todas estas decisões são feitas apenas através de decreto presidencial, ação que é desempenhada em hierarquia política muito acima da escala de atuação do conselho, em um espaço de disputas permeadas por assimetrias de poder em que o conselho tem pouca influência efetiva. Neste caso, a baixa delegação de poder ao conselho o torna um espaço pouco eficiente em gerir os atuais conflitos.

O compartilhamento de poder entre os atores sociais é uma das bases do conceito da co-gestão adapativa (ARMITAGE et al., 2007). Em relação aos 
conselhos em UC a legislação prevê que eles são consultivos com competência para propor e demandar ações (BRASIL, 2000; ICMBIO, 2013). A 'consulta' figura entre os níveis mais baixos na hierarquia de compartilhamento de poder nos processos de co-gestão (ARNSTEIN, 1969; POMEROY; BERKES, 1997). De fato, o nível ideal de compartilhamento de poder depende de cada caso, não é pré-definido e pode aumentar ao longo do tempo (ARMITAGE et al., 2007). Entretanto, é notável que a delegação de poder dado ao conselho é insuficiente se o objetivo é lidar com os conflitos gerados pela restrição de acesso aos recursos devido a criação da ESEC.

\section{Adequação da UC à Realidade Local}

A adequação da ESEC à realidade local passa necessariamente pela gestão dos conflitos visando a compatibilização do uso de recursos pelas comunidades locais com a política de conservação. Porém, como os resultados apontam, o uso dos recursos pela comunidade tradicional, notadamente a pesca do caranguejo, não incide apenas nas áreas da ESEC. Inclui também outras unidades de conservação (APA de Guaraqueçaba e PARNA de Superagui), além de apresentar incompatibilidade com a legislação de pesca vigente a nível estadual e federal (TEBET, TRIMBLE, MEDEIROS, 2018). Portanto, a adequação da UC à realidade local envolve a necessidade de articulações entre escalas institucionais, que garantam no mínimo a gestão integrada entre as unidades de conservação e a coordenação de ações entre as políticas pesqueiras e as políticas de conservação.

A co-gestão adaptativa é apontada como um caminho para se criar arranjos institucionais que permitam a descentralização participativa das tomadas de decisão (compartilhamento de poder) e a conexão coordenada de ações entre diferentes escalas institucionais (ARMITAGE et al., 2009; BERKES, 2007a). Como apontado anteriormente, o conselho da ESEC tem baixa capacidade de coordenar ações com outras instituições ou de afetar diretamente as decisões tomadas em outras escalas políticas, dificultando a adequação da UC à realidade local. Porém, a co-gestão adaptativa é um processo, e o conselho parece estar em estágios iniciais da gestão colaborativa, onde predomina o diálogo e o reconhecimento dos distintos pontos de vista entre os diferentes atores. 


\section{Considerações Finais}

A criação de conselhos em UC é um passo importante na busca por mecanismos de gestão participativa. No caso da ESEC de Guaraqueçaba o conselho cumpre seu papel enquanto espaço de diálogo e aproximação entre atores sociais, mais ainda encontra obstáculos em garantir a participação efetiva e legítima dos diferentes atores sociais, principalmente por ser um espaço pouco adaptado às condições de organização local das comunidades, o que acaba por comprometer o objetivo de ser um espaço de controle social da política de conservação. A gestão de conflitos através do conselho também encontra obstáculos devido principalmente ao baixo compartilhamento de poder delegado aos atores sociais envolvidos, e à dificuldade de se integrar com outras esferas de tomadas de decisão, o que dificulta consideravelmente a capacidade do conselho em adequar a UC à realidade local.

Com base no conceito de co-gestão adaptativa algumas sugestões podem ser feitas visando o aprimoramento do funcionamento dos conselhos. Primeiro, é importante dar atenção aos estágios iniciais de criação dos mesmos, promovendo amplo esclarecimento sobre regras de funcionamento e limitações, evitando criar falsas expectativas. Os objetivos e competências devem ser amplamente discutidos com os atores sociais envolvidos, principalmente devido ao histórico autoritário e centralizador do processo de criação das UC. Segundo, cabe ao governo saber se adaptar às condições locais e flexibilizar a estrutura de funcionamento do conselho visando uma maior integração entre as comunidades, órgãos públicos e outros atores sociais. Esta flexibilização e adaptação nos mecanismos de participação para se integrar ao tipo de organização local existente tornaria muito mais eficiente o controle social e a transparência no processo de gestão. Terceiro, é necessário repensar o grau de compartilhamento de poder proposto, já que, dificilmente propondo e acompanhando ações (competências do conselho) este espaço terá sucesso em gerir conflitos e gerar integração da UC com o planejamento territorial da área de influência (ambas diretrizes do conselho). Finalmente, não há como se pensar a co-gestão adaptativa em UC sem levar em consideração o histórico de criação destas UC e a trajetória das comunidades locais envolvidas.

\section{Agradecimentos}

Agradecemos à CAPES pelas bolsas de mestrado e de pós-doutorado concedidas aos autores. Suporte adicional também foi concedido pelo International 
Development Research Center - Canada-Latin America and the Caribbean Research Exchanges (IDRC - LACREG). Também agradecemos ao Centro de Estudos do Mar (UFPR) em especial ao Núcleo de Pesquisa em Sistemas Pesqueiros e Áreas Marinhas Protegidas (NESPAMP) pelo suporte. Ao ICMBIO, na figura do chefe da Estação Ecológica de Guaraqueçaba, nossa sincera gratidão pelo apoio técnico e logístico. Nosso agradecimento também a todos os conselheiros e comunitários que participaram desta pesquisa.

\section{REFERÊNCIAS}

ABERS, R. N; KECK, M. E. Representando a Diversidade: Estado, sociedade e 'relações fecundas' nos conselhos gestores. Caderno CRH, Salvador, v.21, n. 52, p. 99-112, 2008.

ACHESON, J. M. Institutional Failure in Resource Management. Annual review of Anthropology, v. 35, p. 117-134, 2006.

ANDRIGUETTO-FILHO, J. M. Sistemas Técnicos de Pesca no Litoral do Paraná: caracterização e tipificação. In: Raynaut, C. et al (org.). Desenvolvimento e Meio Ambiente - em busca da interdisciplinaridade. Curitiba: Ed. UFPR, 2002. p. 213-233.

ARAUJO, L.G. et al. Struggle for Inclusive development in small-scale fisheries in Paraty, Southeastern Coast of Brazil. Ocean \& Coastal Management, v. 150, p. 24-34, 2017.

ARMITAGE, D. Building Resilient Livelihoods through Adaptive Co-Management: The role of Adaptive Capacity. In: ARMITAGE, D.; BERKES, F.; DOUBLEDAY, N (org.). Adaptive CoManagement: Collaboration, Learning and Multi-Level Governance. Vancouver: UBC Press, 2007. p. 62-82.

ARMITAGE, D. et al. Adaptive Co-Management for Social-Ecological Complexity. Frontiers in Ecology, v. 7, p. $95-102,2009$.

ARNSTEIN, S. A. Ladder of Citizen Participation. Journal of the American Planning Association, v. 35, n. 4, p. 216-224, 1969.

BERKES, F. Adaptive Co-Management and Complexity: Exploring the many faces of comanagement. In: ARMITAGE, D.; BERKES, F; DOUBLEDAY, N (org.). Adaptive CoManagement: Collaboration, Learning and Multi-Level Governance. Vancouver: UBC Press, 2007a. p. 19-37.

BERKES, F. Community-based conservation in a globalized world. PNAS, v. 104, n. 39, p. 15188-15193, 2007b.

BOCKSTAEL, E. et al. Participation in protected area management planning in coastal Brazil. Environmental Science \& Policy, n. 60, p. 1-10, 2016.

BRASIL. 2000. Lei n 9985 de 2000. - Sistema Nacional de Unidades de Conservação (SNUC). Brasília, DF. 2000.

BRASIL. 2002. Decreto $\mathrm{n}^{\circ} \mathbf{4} .340$ de 22 de agosto de 2002 - Regulamenta artigos da Lei n`9985, que dispõe sobre o Sistema Nacional de Unidades de Conservação. Brasília, DF. 2002.

BUNCE, L; TOWNSLEY, P; POMEROY, R; POLLNAC, R. Socioeconomic Manual for Coral Reef Management. Australian Institute of Marine Science, 2000.

CASTRO JÚNIOR, E; COUTINHO, B.H; FREITAS, L.E. Gestão da Biodiversidade e Áreas Protegidas. In: Guerra, JOSÉ TEIXEITA; COELHO, MARIA CECÍLIA NUNES (org.). Unidades de Conservação: abordagens e características geográficas. Rio de Janeiro: Bertrand Brasil, 2009. p. 25-63.

CHARLES, A; WILSON, L. Human Dimensions of Marine Protected Areas. ICES Journal of Marine Science, n.66, p. 34-47, 2008.

CHUENPAGDEE, R. et al. Marine protected areas: Re-thinking their inception. Marine Policy, v. 39, p. 234-240, 2013.

CUNHA, L. H; COELHO. M. C. N. Política e Gestão Ambiental. In: CUNHA, S. B; GUERRA, A. J. T. (Org.). Questão Ambiental: diferentes abordagens. Rio de Janeiro: Bertrad Brasil, 2009. p. 43-67. 
DAGNINO, EVELINA. Construção Democrática, neoliberalismo e participação: os dilemas da confluência perversa. Política \& Sociedade, n. 5. p. 139-164, 2004.

$\mathrm{FAO}$. La Ordenación Pesquera. 4.Las áreas marinas protegidas y la pesca. FAO Orientaciones Técnicas para la Pesca Responsable. n4. ROMA: FAO, 2012.

FARACO, LUIZ FRANCISO DITZEL. Vulnerabilidade de Pescadores Paranaenses às Mudanças Climáticas e os Fatores que Influenciam suas Estratégias de Adaptação. 2012. Tese (Meio-ambiente e Desenvolvimento)- Curitiba, Universidade Federal do Paraná. 2012.

FOLKE, C. et al. Resilience and sustainable development: building adaptive capacity in a world of transformations. Ambio, v. 31, n. 5, p. 437-440, 2002.

HOOLINGS, C.S; MEFFE G. K. Command and Control and the Pathology of Natural Resource Management. Conservation Biology, v. 10, n. 2, p. 328-337, 1996.

ICMBIO. 2014. Instrução Normativa $n^{\circ} 09$ de 05 de dezembro de 2014 - Disciplina as diretrizes, normas e procedimentos para formação, implementação e modificação na composição do Conselho de Unidades de Conservação. Brasília, DF. 2014

INSTITUTO SOCIOAMBIENTAL (ISA). Almanaque Brasil Socioambiental. São Paulo: ISA. 2008.

JENTOFT, S.; SON, T.J.V; BJORKAN, M. Marine Protected Areas: A Governance System Analysis. Human Ecology, n. 35, p. 611- 622, 2007.

KALIKOSKI, D. C. Áreas Marinhas Protegidas, Conservação e Justiça Social: Consideração a luz da Teoria dos Comuns. In: MINISTÉRIO DO MEIO AMBIENTE (org.). Áreas Aquáticas Protegidas como Instrumento de Gestão Pesqueira. Brasília: MMA, 2007. p. 55-68.

KEARNEY, J; BERKES, F. Communities of Interdependence for Adaptive Co-Management. In: ARMITAGE, D.; BERKES, F; DOUBLEDAY, N (org.). Adaptive Co-Management: Collaboration, Learning and Multi-Level Governance. Vancouver: UBC Press, 2007. p. 191-207.

LOUREIRO, C. F. B.; CUNHA, C. C. Educação Ambiental e Gestão Participativa em Unidades de Conservação: elementos para se pensar a sustentabilidade democrática. Ambiente \& Sociedade, v. 11, n. 2, p.237 - 253, 2008.

OLSSON, P.; FOLKE, C.; BERKES, F. Adaptive comanagement for building resilience in social-ecological systems. Environmental management, v. 34, n. 1, p. 75-90, 2004.

PAULA, S. P.; MEDEIROS, R. P.; TRIMBLE, M. Impacts of institucional Changes and MPA Management to Tradicional People's Livelihood and Food Security in Southern Brazil. In: Conference of the International Association for the Study of the commons (IASC Conference) Canada. 2015.

PLUMMER, R; ARMITAGE, D. A Resilience-Based Framework for Evaluating Adaptive CoManagement: Linking ecology, economics and society in a complex word. Ecological Economics, v. 61, p. 62-74, 2007.

PLUMMER, R. et al. Adaptive Comanagement: a Systematic Review and Analysis. Ecology and Society, v. 17, n. 3, 2012.

POMEROY, R.S; BERKES, F. Two to Tango: the role of government in fisheries. Marine Policy, v.21, n.5, p. 465-480, 1997.

POMEROY, R.S; PARKS, J.E; WATSON, L.M. How is Your MPA Doing? A Guidebook of Natural and Social Indicators for Evaluating Marine Protected Areas Mangement Effectiveness. IUCN, Gland, Switzerland and Cambridge, UK. 2004.

REED, M.S. Stakeholder Participation for Environmental Management: A literature review. Biological Conservation, v. 141, p. 2417-2431, 2008.

SANDSTROM, A; CRONA, B; BODIN, O. Legitimacy in Co-management: The impact of preexisting structures, social networks, and governance strategies. Environmental Policy and Governance, v. 24, p. 60-76, 2014.

SEIXAS, CRISTIANA SIMÃO. Abordagens e Técnicas de Pesquisa Participativa em Gestão de Recursos Naturais. In: VIEIRA, P. F; BERKES, F; SEIXAS, C. S (org.). Gestão Integrada e Participativa de Recursos Naturais. Florianópolis: Secco/APED, 2005. p. 73-108. 
TEBET, G.C.C; TRIMBLE, M.; MEDEIROS, R.P. Using Ostrom's Principles to Assess Institutional Dynamics of Conservation: Lessons from a Marine Protected Area in Brazil. Marine Policy, v. 88, p. 174-181, 2018.

TRIMBLE, M.; PLUMMER, R. Participatory evaluation for adaptive co-management of social-ecological systems: a transdisciplinary research approach. Sustainability Science, v. 14, p. 1091-1103, 2019.

\section{NOTAS DE AUTOR}

\section{CONTRIBUIÇÃO DE AUTORIA}

Guilherme Tebet - Concepção, coleta de dados, análise de dados, elaboração do manuscrito, revisão da versão final do trabalho

Micaela Trimble - Concepção, coleta de dados, participação na análise e discussão dos resultados, revisão do manuscrito nas diferentes etapas.

\section{FINANCIAMENTO}

Bolsa de mestrado (G. Tebet) e pós-doutorado (M. Trimble) concedida aos autores pela CAPES. Suporte adicional concedido pelo International Development Research Center - Canada-Latin America and the Caribbean Research Exchanges (IDRC-LACREG) para a coleta de dados em campo.

\section{CONSENTIMENTO DE USO DE IMAGEM}

Não se aplica

\section{APROVACC̃̃O DE COMITÊ DE ÉTICA EM PESQUISA}

Não se aplica.

\section{CONFLITO DE INTERESSES}

Não se aplica.

\section{LICENÇA DE USO}

Este artigo está licenciado sob a Licença Creative Commons CC-BY. Com essa licença você pode compartilhar, adaptar, criar para qualquer fim, desde que atribua a autoria da obra.

\section{HISTÓRICO}

Recebido em: 01-02-2019

Aprovado em: 03-09-2019 